\title{
Un urbanismo de la observación. Metodologías prospectivas en torno a la idea de calle ciudad en tres capitales andaluzas (Córdoba, Málaga y Granada)
}

Juan Luis Rivas. Universidad de Granada, Granada, España.

RESUMEN | Las ciudades del sur de España tienen en la ordenación de su territorio un reto mayúsculo. $\mathrm{Al}$ aumento de la diversidad de formas y tiempos del urbano contemporáneo, se suma un incremento de relaciones, sensibilidades y niveles de gobernanza en una coyuntura socioeconómica muy difícil e incierta. En este contexto se reconoce una necesidad de cambio de paradigma en relación con el urbanismo heredado, un camino que permita una renovación metodológica de sus criterios de actuación y relación con la sociedad. Desde esta perspectiva, en este artículo se exponen los resultados de una investigación sobre la calle ciudad, una lectura específica de tres ciudades andaluzas. La calle ciudad es definida como un elemento urbano complejo perteneciente a cada ciudad, a través del cual observar el conjunto urbano. Mediante análisis propositivos y series cartográficas que atienden a la multiplicidad, las metodologías presentadas apuestan por un urbanismo descriptivo y crítico que sirva para profundizar en el conocimiento de los territorios urbanos.

PALABRAS CLAVE | urbanismo, planificación urbana, estructura urbana.

ABSTRACT | Cities in southern Spain have a huge challenge when it comes to organizing their territories. The intensification of relationships, sensibilities and varying levels of governance, in the context of very difficult and uncertain socioeconomic circumstances adds to the diversity of various forms and times regarding contemporary urban space. In this context, there is a need for a paradigm shift in traditional urbanism that allows for methodological renovation regarding both criteria for intervention and a rewnewed relation with society. Along these lines, this article presents the results of research on the city street, a specific study of three Andalusian cities. The city street is defined as a complex urban element pertaining to each city, through which the urban ensemble is perceived. Through forward-looking analysis and cartographic examples that display a wide-ranging variety of city-streets, the methodologies presented call for a more descriptive and critical urbanism that will enhance the consciousness of urban territories.

KEYWORDs | urbanism, urban planning, urban structure.

Recibido el 31 de mayo de 2013, aprobado el 16 de enero de 2014

E-mail: juanluisrivas@ugr.es

Correspondencia: Departamento de Urbanística y Ordenación del Territorio, Calle Severo Ochoa s/n, Campus de Fuente Nueva, 18071 Granada, Espańa 


\section{Introducción}

El territorio urbano contemporáneo parece expandir sus fronteras sin mayores restricciones al mismo tiempo que aumenta su complejidad. Paralelamente a este proceso físico y también socioeconómico, las administraciones responsables de la ordenación del territorio y del urbanismo han ido recogiendo en las últimas décadas los segmentos disciplinares que se hacían fuertes -centrados en las infraestructuras, el patrimonio, la protección del medioambiente, el turismo, el comercio, la vivienda, etcétera-, y les han dado en muchos casos autonomía legislativa y poder decisorio en la ecuación urbana.

En España, particularmente, el fortalecimiento de las autonomías -que observamos imparable-, al mismo tiempo que el peso del municipalismo, han convertido el territorio urbano en un campo superpuesto de todo tipo de regulaciones, sirviéndose para ello de los planeamientos generales urbanos, así como de los planeamientos supramunicipales de tipo metropolitano. En último término, ha sido un intento de controlar la difusión espacial, la mezcolanza ciudad-campo, la mala praxis edificatoria, la fragilidad ambiental o la distancia entre gobiernos y ciudadanos, al tiempo que se trata de domesticar cambios socioeconómicos que se han mostrado casi inevitables. Es un proceso similar a los que se han podido producir en los países europeos del entorno, Italia, Portugal o Francia, y también en otros muchos países latinoamericanos.

Sin embargo, este incremento normativo y este esfuerzo delimitador de competencias y definidor de cada vez más contornos administrativos, con ordenamientos específicos, no han logrado los fines esperados, genéricamente hablando. En la balanza de lo positivo, es una realidad que el urbanismo reciente ha logrado evidentes progresos sectoriales en cuanto al incremento de sensibilidades históricas, ambientales o sociales. No obstante, otros síntomas -como la desorganización de las rentas del suelo, sus burbujas globales y locales, el dominio de la voluntad privada de las grandes empresas en la localización de usos e infraestructuras o la persistencia de las irregularidades e ilegalidades urbanísticas, por ejemplo- muestran cómo, paradójicamente, este territorio "híper-planificado" parece encontrarse en la práctica cada vez más liberalizado.

Resulta bastante evidente que por el camino de la acumulación lineal de reglas y aspectos necesarios de considerar, no se ha logrado, al menos en este contexto, un efectivo acercamiento entre la teoría y la práctica de la planificación, ni tampoco una buena comunicación con la sociedad. Esto es más acentuado aún en las ciudades de tamaño medio y en sus entornos", a diferencia de las ciudades "capitales", donde el planeamiento heredado de tipo "ensanche" -Barcelona, Madrid, Valencia, entre otras-, la densidad poblacional, la actividad económica diversificada, la capacidad para captar inversiones privadas potentes, la producción de ciudad burguesa, la presencia de una administración con presupuesto y las capacidades culturales y de innovación del conocimiento, han sido casi constantes desde hace mucho más tiempo. 300.000 y 700.000 habitantes, incluyendo sus áreas metropolitanas o entornos urbanos. 
Por todo lo anterior, de manera especialmente necesaria en este tipo de ámbitos, la técnica urbanística debería cuestionarse sus principios orientadores y reconsiderar sus modos y sus actitudes. Recordar ciertas bases constituyentes que en algunos momentos de la historia de las ciudades y del urbanismo fueron espléndidamente formuladas puede resultar interesante, y también hacerlo desde una perspectiva actual que tenga en cuenta las conquistas del modelo sociocultural y económico imperante, así como sus deficiencias y dificultades.

En este sentido, la forma de aproximación a lo urbano a través de la calle ciudad se presenta como muestra de un necesario urbanismo de la observación que apuesta por "comprender el territorio", reflexionando acerca de sus características y de los procesos habituales para su planificación, que nos sitúan hoy ante esta necesidad de introspección.

Definida, básicamente, como un conjunto de elementos y relaciones urbanas vertebradas alrededor de una calle relevante del entramado urbano, la calle ciudad es utilizada, a través de un repertorio metodológico asimétrico, como instrumento para interpretar cada ciudad y orientar su crítica.

\section{La necesidad de un cambio de paradigma}

\section{Un territorio urbano complejo y diverso}

Desde un punto de vista conceptual, el territorio urbano se ha extendido en las últimas décadas hasta coincidir prácticamente con el conjunto integral del territorio. En él podemos encontrar ciudades de todos los rangos y tamaños posibles, y también territorios no urbanos, paisajes agrarios o naturales. Pero en el territorio intervienen también todos los espacios intermedios y la relación entre sus partes: carreteras, áreas de servicio, crecimientos exurbanos, polígonos tecnológicos, etcétera.

Necesitamos entender esta sumatoria como un todo-unidad inseparable que conserva sus diferencias internas y genera, cada vez más, mecanismos complejos de relación, nuevas actividades y formas urbanas o pseudourbanas. El urbanismo reciente se ha esforzado por acercarse a tal complejidad desde los diferentes campos disciplinares que en él se concitan y atravesando lógicas y corrientes más o menos locales, lo que ha derivado en un sinfín de teorías que tratan de capturar parte de estos significados. De entre los conceptos derivados de todas ellas, propondríamos señalar aquí algunos especialmente útiles, que remiten a variables actuales de lo urbano muy significativas y discutidas: el tiempo, la acumulación y la gestión del espacio.

Para empezar, vivimos en un espacio y tiempo concretos, conscientes de un zeitgest particular y propio, aquel que nos permite ser específicos en el tratamiento y la valoración de cada entorno, dando pie a una perspectiva más amplia y seguramente más justa ${ }^{2}$. En él se desarrollan las actividades urbanas con sus acentos particulares, hábitos e innovaciones que marcan algunas cualidades del territorio más que otras. Dicho de otro modo, el zeitgest polariza los materiales con que las ciudades están hechas y la forma y los instrumentos con que debemos juzgarlas.

2 Zeitgeist es una expresión alemana que significa "el espíritu (Geist) del tiempo (Zeit)". Denota el clima intelectual y cultural de una era. Eisenman (1995) utilizaba esta definición en los años ochenta para justificar su arquitectura alejada de "lo clásico". 
Por otro lado, el reclamo de la cualidad sedimentaria está presente desde el origen de la teoría urbanística (Geddes, McHarg, Aymonino, Rossi, Muratori, Pannerai...). Aprender de las formas urbanas que se van superponiendo desde la fundación de la ciudad se convirtió para muchos en motor de la crítica y, en definitiva, del proyecto o la planificación. "La ciudad, como objeto de la arquitectura, es siempre una reescritura de una ciudad anterior (...). A otro nivel, nos enfrentamos también al plano urbano, que puede verse como el terreno en el que las trazas se graban y retienen indefinidamente mientras cambia todo lo demás" (Gandelsonas, 1990a, p. 67).

Por su parte, el historiador André Corboz (2004), a través de la idea de "palimpsesto urbano", define el territorio como un "proceso", en presente continuo de acciones en marcha; un "producto" resultante de la acumulación de estados pasados de sí mismo; y también un "proyecto", de futuros probables o no tanto, de intenciones y orientaciones deseables. Y es que nos enfrentamos hoy al conjunto heredado de formas anteriores en convivencia con la forma actual, y también a los cambios sociales, políticos y económicos, cambios incluso en el lenguaje urbano. Surgiría así la posibilidad de parar el tiempo precedente en cualquier momento, confrontar esa forma con la que actualmente vemos y aprender de sus diferencias.

Por otro camino bien distinto, la arquitectura del pasado siglo se enzarzó en una fructífera discusión sobre la relación entre forma y función, en especial con los postulados del Movimiento Moderno, sus derivadas y sus oposiciones. La muy criticada práctica deconstructivista investigó relaciones más libres de la forma y enriqueció sus posibilidades generativas y de explicación del espacio. Más concretamente, Peter Eisenman, a través de dualidades terminológicas sobre la forma, nos ayudó a entender la doble condición espacial de "la ciudad artificial" asentada sobre "el lugar natural": sistema geométrico frente al sensible, forma genérica frente a la específica, forma desde la arquitectura frente a la forma desde el contexto, etcétera ${ }^{3}$. Eisenman insiste con su propio lenguaje en el ámbito de lo conceptual, despreciando los muy valorados aspectos visuales. Para él, contexto significa aceptar la existencia de un marco físico como punto de partida del proyecto, un campo magnético que, aunque parezca deformar o deconstruir la realidad, orienta el trabajo (Figura 1).

Con estas ambivalencias y movimientos dialécticos, la arquitectura crítica de final de siglo pasado se acerca también a una realidad cada vez más cambiante y prepara para la admisión de significados múltiples.

\section{Una planificación disfuncional}

Para afrontar el estudio y la ordenación de una realidad de tal complejidad, es necesario centrarse también en observar la planificación urbanística y tratar de llevar a cabo una evaluación. eisenmaniana que utilizó Ignasi de Solá-Morales (1989) (extrañamiento, materialización, metáfora y hermenéutica), que se construye por la distancia entre dos signos que evocan algún tipo de analogía. 
Figura I | "Vértice territorial" entre la calle Arabial y el camino de Purchil (Granada), frontera oeste entre la ciudad y el espacio abierto

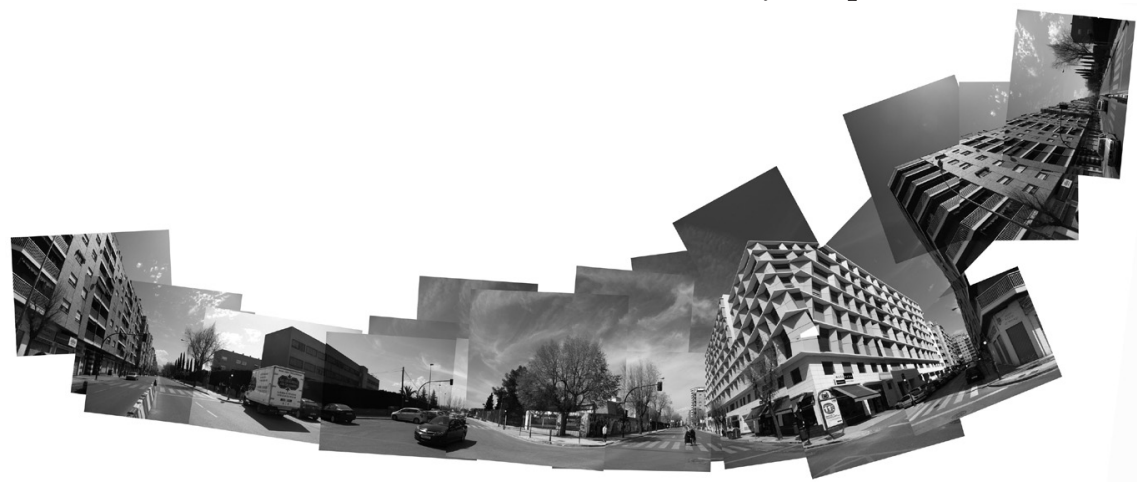

FUENTE ELABORACIÓN PROPIA

Es una tendencia internacional generalizada el hecho de considerar superado, en principio, aquel debate entre plan y proyecto de finales del siglo pasado, animado especialmente por la literatura urbanística italiana o española (Secchi, 1984; SoláMorales, 1987). Tal disyuntiva se resolvió asumiendo la compatibilidad de ambos instrumentos de ordenación y valorando la necesidad de su relación biunívoca. Mientras, en estos años, han ido ganado protagonismo otras fórmulas más o menos distintas: planes sectoriales -patrimoniales, de movilidad, de infraestructuras...-, especiales, temáticos, estratégicos, etcétera. Más concretamente, en España se está percibiendo desde hace tiempo una saturación de acciones de planificación y una sobredimensión de la administración en un periodo económico, además, bajo mínimos históricos. No solo hay demasiados planes, también los planes son excesivamente profusos en nimiedades, exigidos hacia el detalle normativo, hacia el control de la casuística, por muy dispar que esta demuestre ser. Todo ello debiera conducir al cuestionamiento de la acción reguladora "parcela por parcela" como patrón metodológico del planeamiento presente y futuro.

$\mathrm{Y}$ es que las cuestiones urbanas estructurales son muy poco discutidas en procesos verdaderamente participados, desdibujándose dentro del maremágnum en que acaban convirtiéndose los procesos de redacción del planeamiento: dilación en las aprobaciones, nulo impulso para la participación pública, falta de entramados sociales con fines colectivos, intromisiones políticas en la técnica, obsolescencia instrumental, etcétera. Planes de este tipo suelen resultar incapaces de dialogar adecuadamente con otras escalas, despegados como están de las demandas o potencialidades del "urbanismo local", sin medir o anticipar sus incidencias.

En Andalucía, pero no solo en esta región, donde la administración regional persiste en repartir homogéneamente políticas e inversiones ${ }^{4}$, se ha extendido una desmedida atención a la ordenación pormenorizada que menoscaba, y en algunos casos impide, la reflexión sobre las grandes cuestiones urbanas actuales de cada

Sin contar con los desequilibrios producidos por el centralismo que representa Sevilla y que es considerado por el resto de Andalucía como parcialmente evitable. 
ciudad, sobre acotaciones o lugares específicos que son fundamentales para entender los ámbitos de planificación.

En estos momentos, cuando el contexto geopolítico es de una profunda crisis presupuestaria y de confianza, plantear un urbanismo que economice medios y enfoque con precisión sus prioridades se hace imprescindible. Este urbanismo, estratégico pero a la vez concreto, se presenta recordando muchas de las características que definían aquel "proyecto urbano" (Solá-Morales, 1987) que operaba como un mediador con gran aplicabilidad, pero obligado también ahora a tomar responsabilidades de gran escala, compromisos metropolitanos o regionales.

Estas reflexiones remiten a una planificación urbanística que, en la práctica, no está a la altura de los avances teóricos de la disciplina y se muestra incapaz de recoger sus lecciones. En esta distancia y en estas dificultades se sustenta la apuesta por un cambio de paradigma que es, en contextos de este tipo, más que necesario: un urbanismo que surja de lo parcial para atender también a lo general, que reclame un tiempo para la investigación y para la crítica (especialmente ahora, cuando han disminuido las presiones de la acción y la inversión). Este urbanismo -esta actitud, si se quiere- es también útil para el conjunto de la disciplina, como modus operandi que siempre estuvo incorporado a su repertorio, independientemente de las coyunturas espaciales, políticas y socioeconómicas, sea transversal a las tendencias del urbanismo generadas durante el siglo xx (Dematteis, 2006; Meyer, 2005) ${ }^{5}$.

\section{Instrumentos para un urbanismo de la observación}

\section{Geddes y la "visión sinóptica"}

El pensamiento de Patrick Geddes, expresado de forma sistemática en su Ciudades en evolución (1915/2009), no deja de resultar cautivador con el paso de los años. Su poderosa influencia en autores como Mumford o McHarg -referencias a su vez del urbanismo, la ordenación del territorio y la ecología del paisaje actuales- no resta a su aportación autónoma, ya que en muchas cuestiones vislumbró un panorama radicalmente acertado y se preocupó por cuestiones que aún hoy siguen estando pendientes.

Algunos de los principales problemas de la planificación contemporánea tienen su raíz en la falta de consideración o de intensidad con que son tratados algunos de los asuntos que más preocuparon a Geddes. Es un hecho que las dimensiones de su survey before planning no han sido en buena parte alcanzadas por la planificación actual, que parece operar siempre en virtud de la selección entre alternativas prefijadas. El análisis que él demandaba tenía particularidades muy interesantes que han sido obviadas o minusvaloradas, incluso desde campos y prácticas aparentemente más cercanas ${ }^{6}$. Así, el biólogo y urbanista escocés vinculaba el estudio de las

Meyer (2005) describe el urbanismo en tanto que disciplina científica según varias corrientes: la evolución en las posiciones de las facultades de Arquitectura, las investigaciones científicosociales, la investigación a través del diseño, los análisis de la forma, las reflexiones filosóficaculturales sobre el diseño, los estudios urbanos contemporáneos, etcétera. Dematteis (2006) definió a través del concepto de "territorialidad" dos orientaciones del urbanismo: una dirigida a la producción de normas de uso de los recursos disponibles y otra encaminada hacia los procesos interactivos para la creación e incremento de los valores urbanos.

6 Ciertos campos científico-sociales del urbanismo: parte de la geografía, de las ingenierías, de 
ciudades con el "análisis preparatorio", concepto clave que se debía llevar a cabo a través de dos instrumentos: el observatorio y las exposiciones cívicas. A ello se sumaba una apuesta por la intensidad de la componente práctica, por una interacción con el medio estudiado desde la participación y la observación directa.

En Edimburgo, su Outlook Tower le permitía tener una visión completa de la ciudad y de sus alrededores y alcanzar ese análisis sistemático de su origen y desarrollo (Figura 2): “[un] incipiente Observatorio Cívico y Laboratorio a la vez, un tipo de institución necesaria en cada ciudad, con su esfuerzo en aras de la relación entre pensamiento y acción, ciencia y práctica, sociología y ética, con su contraseña y empresa del "Análisis urbano para el servicio cívico" [Civic Survey for Civic Service]" (Geddes, 1915/2009, p. 505).

Figura 2 | Instrumentos de Geddes: (izq.) Plano de la Exposición de Ciudades y Urbanismo de Gantes, 1913; (der.) Diagrama de la Outlook Tower
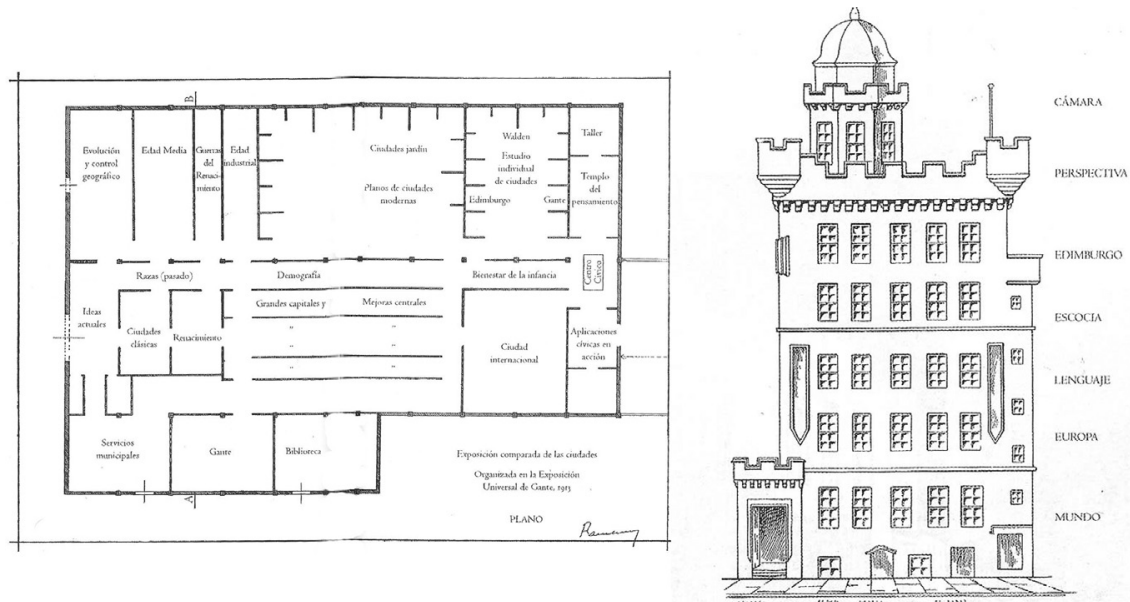

FUENTE GEDDES (I9I 5/2009, PP. 478 Y 554)

Las Exposiciones Cívicas y de Urbanismo, itinerantes y alojadas según la ciudad en un edificio emblemático, servirían para "percibir y no perder de vista el espíritu y la individualidad de nuestra ciudad, su personalidad y su carácter, y realzarlo y expresarlo si no queremos seguir borrándolo y reprimiéndolo" (Geddes, 1915/2009, p. 28). Respondían, así, también a la necesidad de comunicar a los demás, ayudando al auge del estudio de las ciudades como ciencia social experimental.

De la misma manera, la "visión sinóptica" que Geddes definió puede ser muy esclarecedora para afrontar los contextos espaciales y las coyunturas socioeconómicas actuales. Por mucho que contemplara la idea de totalidad, tal visión no se producía exclusivamente a través del acopio inacabable de información objetiva,

\footnotetext{
las ciencias ambientales o de la ecología del paisaje, y aquellos empeños por definir tipos de problemas y de soluciones posibles y reglas de funcionamiento. Así también, especialidades dentro de los estudios urbanos contemporáneos que establecen categorías de acción según casos, pueden hacer perder peso, si son malinterpretadas, a las dimensiones específicas del objeto físico y social, a las posibilidades de su estudio y su proyecto.
} 
como parecería deducirse de la actitud exhaustiva y fría con que muchos simplifican hoy el conocimiento del territorio ${ }^{7}$. Se alimentaba también de imágenes desconocidas (producto más o menos inesperado de los reflejos en la camera obscura de la última planta de su observatorio) y era capaz de encontrar elementos de corte o sintéticos, como la "sección del valle": unidad geográfica característica que permitía leer la globalidad, una teoría para explicar la evolución de la región.

El centro argumental de su pensamiento remitía, en fin, a un urbanismo preocupado por un conocimiento mejor de las ciudades y que, como él mismo dejó escrito, debía "aprender viviendo", construyendo una teoría mezclada e iluminada por la práctica.

\section{Cartografías prospectivas y lenguajes urbanos}

El territorio profundo y complejo que reconocía Geddes es hoy más que nunca un crisol de materiales urbanos. Para alcanzar ese "estar como en casa" que él reclamaba se debería conseguir hablar el lenguaje del territorio: un grado de empatía tal con el medio que permitiera entender, más allá de los hechos urbanos, el modo con que están tejidas sus relaciones. Es por ello que el urbanismo lleva décadas esforzándose por aproximarse a los territorios desde una perspectiva recopilatoria, descomponiéndolo y recomponiéndolo una y otra vez. Se trata, con frecuencia, de métodos constructivos que distinguen las partes o componentes del conjunto, valoran su protagonismo generando jerarquías, y fundamentan la creación de ámbitos especiales de intervención.

Tal fue el trabajo de representación de las Comarcas Catalanas que llevó a cabo el Laboratorio de Urbanismo de Barcelona a principio de los ochenta ${ }^{8}$. Este grupo de profesionales y estudiantes trató de encontrar los elementos constitutivos de la imagen comarcal, los posibles modos de representación por usar, tanto en términos instrumentales como desde su capacidad comunicativa. Resultaba esencial comprender cada territorio como una composición específica, huyendo de representaciones "según manchas homogéneas". "Es toda la historia social la que está escrita en la disposición de los caminos, en los lugares de cruce y de intercambio; en la roturación de cultivos (...); en las formas de la propiedad, en el emplazamiento de las industrias, el crecimiento de las ciudades, los impactos de las infraestructuras" (Solá-Morales, 1981, p. 3).

Esta minuciosidad quedó representada en los planos según dos visiones: la visión arquitectónica del territorio, que reconocía las huellas de construcción del ser humano; y la visión catastral del territorio, que conducía a la idea de catálogo o inventario (Figura 3).

7 Esto es común en las interpretaciones que en muchos casos se han hecho de las ideas y métodos de McHarg (2000).

8 El encargo consistió en dibujar, en un solo plano, las distintas comarcas para los primeros ayuntamientos democráticos, en idéntico tamaño y escala (Solá-Morales, 1981). 
FIGURA 3 | Doble visión del plano de Granada: (izq.) "Esencia del territorio urbano"; (der. de arriba abajo) Ideas territoriales: "Radialidad y ciudad central", "Paralelismo EO" y "Radicalidad interna".

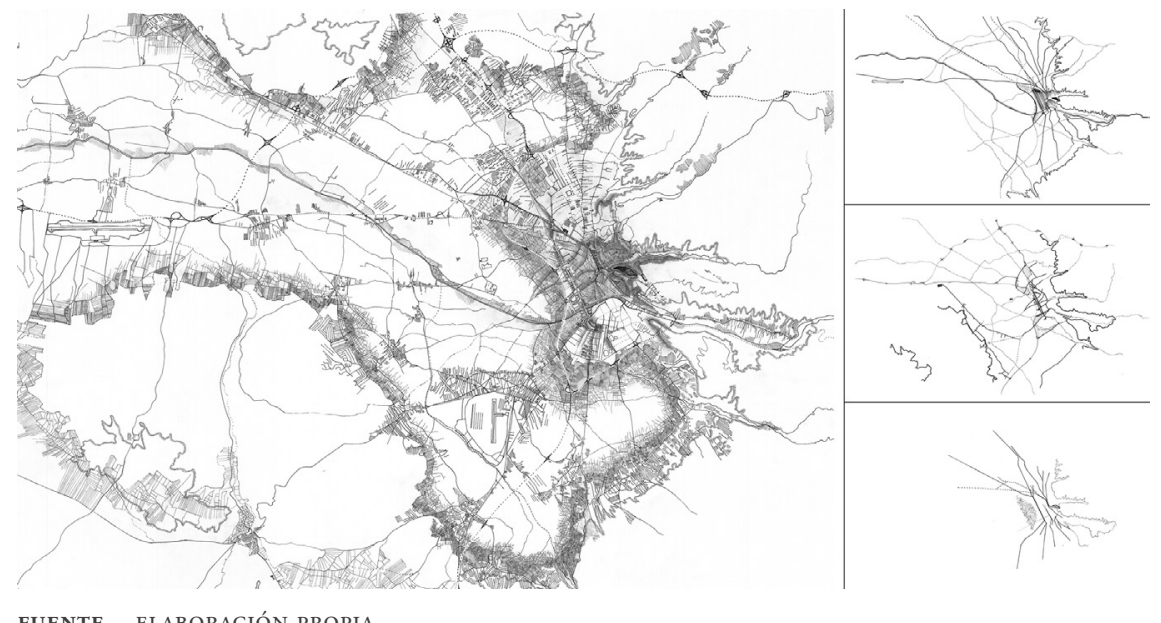

A pesar de esfuerzos de este tipo, es un hecho más que evidente que una parte de la planificación urbanística actual continúa priorizando la producción de "cartografía finalista" frente a la "cartografía prospectiva" (al menos en muchos de los casos españoles y en Andalucía).

Por "cartografía finalista" puede entenderse aquella que refleja solo las acciones y reglas futuras, producto casi exclusivo de procesos de planeamiento que menosprecian una y otra vez las capacidades de las fases de diagnóstico y análisis y, en definitiva, la utilidad de la producción de "cartografía prospectiva". Así, inundan el panorama gráfico del planeamiento aprobado en Espańa, planos de usos y normas de una simpleza enorme, demasiado al dictado de las calificaciones y clasificaciones de las sucesivas leyes del suelo?. Tales mapas, como síntoma de una atonía preocupante, deberían dejar paso a la espesura de las representaciones de procesos y hechos del territorio sedimentado, cartografías colectivas, visiones de la realidad y escenarios, que se construyen "con capacidad crítica para seleccionar el pasado, y con óptica de largo alcance en sus criterios de aprovechamiento y utilidad” (Solá-Morales, 1981, p. 3).

Así también, diversos autores han venido demostrando la validez de las metodologías de búsqueda: Gandelsonas (1999b), reescribiendo la ciudad americana; Viganò (2001), descifrando el territorio del Salento; Portas, Domingues y Cabral (2007), describiendo tendencias y oportunidades del Portugal urbano; Zahonero (2009), representando los paisajes de excelencia en las comarcas de Girona, etcétera, buenos ejemplos de lenguaje expresivo y específico, que asume la complejidad del territorio y de la ciudad y rentabiliza sus diferencias.

9 La primera Ley del Suelo en España se aprobó en 1956 y posteriormente le han seguido las de 1975, 1990 y 1998. En 2002 se aprobó la Ley de Ordenación Urbanística de Andalucía (LOUA), ya con las competencias en materia de urbanismo y ordenación del territorio. 
¿Qué papel desempeña entonces el urbanismo en estas geografías en evolución, qué cualidades se le exigen?

\section{El arraigo elástico del urbanismo en el territorio: escalas y tiempos}

En primer lugar, para que el urbanismo pueda enfrentarse a esta complejidad, se hace necesario reflexionar más que nunca sobre su capacidad para el movimiento entre escalas. Puede decirse que buena parte de sus fracasos ha tenido su base en la falta de una "mirada multiescalar" más interiorizada (Rivas, 2006a). Desde el punto de vista de la producción técnica de las ideas por parte de los técnicos o especialistas, los planes han respondido en muchas ocasiones a uno solo de los niveles de relación del espacio en cuestión ${ }^{10}$. Pero el hecho de que en cualquier punto del territorio actúen, a la vez o intermitentemente, muchas escalas de la realidad exige un esfuerzo intencionado y explícito adicional. Este esfuerzo muy rara vez se hace y por ello podemos encontrarnos con planes, proyectos o políticas que han atendido desmesuradamente a las escalas económicas regionales, desatendiendo las relaciones locales; o que, ensimismados en preocupaciones inmediatas o demandas iniciales del programa, no han sabido aprovechar las lógicas geográficas o de gran escala proporcionadas durante el proceso de planificación. Al territorio se le ha desposeído intrínsecamente de criterios de "multiescalaridad" y es ahora, que se está consolidando la construcción de una verdadera ciudad territorio, cuando esta cualidad propia del buen urbanismo del siglo xx se vuelve imprescindible ${ }^{11}$.

En segundo lugar, el salto cualitativo en la investigación territorial -de la que debieran surgir las ideas- se produce cuando, sumada a las preocupaciones espacial y temática (medioambiental, patrimonial, social, infraestructural, etcétera), se tiene presente una preocupación temporal.

El tiempo es una variable que multiplica la realidad urbana por siglos, décadas, años...; o bien la cualifica por épocas: el territorio preurbano, urbano o posurbano (Soja, 1998). El tiempo polariza elementos y figuras de plano, formas del territorio según tipos de cultura o tipos de movilidad: la ciudad de los caminos, la ciudad de las carreteras, la ciudad de las autopistas, etcétera (Rivas, 2006b).

De esta doble atención a lo múltiple (escalas y tiempos) podrían derivarse tres cualidades importantes de los instrumentos necesarios para la observación:

a. Participan de la geografía base o natural, revitalizándola.

b. Se relacionan directamente con los grandes conjuntos urbanos, activando relaciones entre sistemas.

c. Contienen información multiescalar, dejándose influir por direcciones tanto lejanas como cercanas, tanto por momentos fundacionales como por innovaciones positivas.

10 En relación con las capacidades descriptivas y propositivas del nivel técnico, al margen de la atención, ajuste y verificación de planteamientos colectivos o de consenso, que representan otra posibilidad de evitar este déficit escalar o de relaciones.

11 Ejemplos tan diversos como la lectura múltiple de los patterns encadenados de Christopher Alexander (1977), o las fusiones de tipología, paisaje y construcción del proyecto de Álvaro Siza en Quinta da Malagueira (Évora, 1973-1977). 
Este urbanismo del que hablamos se fija a los sitios de un modo mucho más importante que a través de sus cuestiones perceptivas o formales: se identifica con la geografía concreta y se mueve según el conocimiento de las dinámicas propias de ese territorio, acompañándolo. A través de este arraigo elástico, el urbanismo se justifica, se calibra y adopta posiciones, determinando también sus distintos grados de transformación.

\section{La perspectiva desde la "calle ciudad"}

\section{Del corte urbano al concepto de calle ciudad}

La sección fue siempre uno de los principales instrumentos para el desarrollo de la arquitectura como lenguaje creativo. Fue un invento que permitió la relación entre los elementos situados en planta y su cualidad tridimensional, produciendo algunos avances cruciales: la proporcionalidad y la forma de la columna dórica, la elevación del plano del suelo de las casas de Mies, la comunicación con la media distancia de la Unité d"Habitation de Le Corbusier o la idea de la sección libre de Koolhaas. La sección distinguía espacios que en planta resultaban similares, modulaba secuencias espaciales, establecía compresiones o descompresiones en los recorridos, umbrales de paso, etcétera ${ }^{12}$.

Sin embargo, en el urbanismo, el despegue hacia la dimensión vertical pareció siempre entrañar mayor dificultad (antes de la visión holística que proporcionaron, por ejemplo, sus enfoques geográficos o desde la ecología del paisaje), siendo la planta un instrumento tradicionalmente dominante. Ha sido cuando se ha sabido profundizar precisamente en la cualidad vertical, que se han producido algunos de sus progresos significativos: la ciudad vertical de Hilberseimer, los cruces viarios del Plan Pampus de Bakema, la Teoría de las Siete V en el Chandigarh de Le Corbusier, las plataformas peatonales elevadas del Haupstadt de los Smithson en Berlín, etcétera.

Pero, además, la sección tiene la enorme cualidad de poner en relación lugares distintos de la planta a través de la idea de corte, una acción reveladora tanto de la organización interna de los tejidos como de su forma urbana global (Solá-Morales, $2008)^{13}$. En este segundo sentido, el corte urbano se comportaría como un instrumento descriptivo, un "atravesamiento conceptual" de la realidad que necesita de intención (o dirección), un objetivo fundamental que guía la acción de mirar, de recopilar y describir. El corte selecciona unos elementos en lugar de otros y presenta la capacidad, además, para incorporar elementos sociales, iconografías, textos o pensamientos, tal y como hicieran Strobl o Koolhaas en sus collages interpretativos

12 Recordemos cómo Adolf Loos asignaba una altura concreta a cada habitación en función de su programa en la vivienda, o como Manuel de Solá-Morales proporcionó distinta luminosidad a los espacios en sección bajo la superficie del Moll de la Fusta.

13 Se nos presenta aquí un instrumento surgido de la tradición de análisis formal que emana del salto escalar de la arquitectura hacia el urbanismo de países como Espańa, Italia, Holanda, entre otros, enmarcados en las investigaciones a través del diseño (Meyer, 2005), punto de vista que incorpora, además, aspectos históricos, geográficos, antropológicos y culturales habituales en la arquitectura. 
de Roma y Nueva York (Figura 4). Porque lo que hace útil a la sección es precisamente la ruptura de las fronteras espaciales que el afán clasificatorio del urbanismo representa, estableciendo unidades formales heterogéneas y sui géneris ${ }^{14}$.

\section{FIgURA 4 Collages interpretativos: (izq.) Una operante historia urbana di Roma,} A. Strobl (1963); (der.) The city of captive global, R. Koohass (1978)
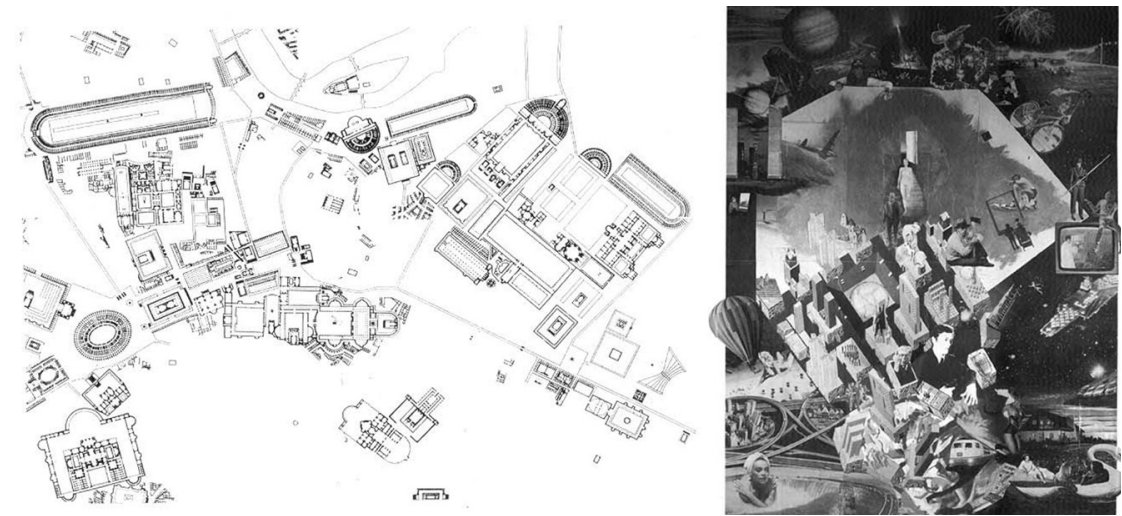

FUENTE (IZQ.) E. BACON, design of cities (I973), P. 84; (DER.) R. KOOLHAAS, delirious new york (I978), P. 295

El concepto de calle ciudad tuvo su antecedente principal en un trabajo de análisis sobre centros históricos en las ciudades medias en Andalucía (Gómez, Grindlay \& Valenzuela, 2004) ${ }^{15}$. Estos núcleos, tradicionalmente compactos, comenzaban a enfrentarse a nuevas lógicas "globales": incremento de las comunicaciones, interacción con el sistema regional de ciudades, etcétera. Para recuperar su específica dimensión urbana, se planteó pensar la ciudad media según sus elementos concretos, sus problemas locales. Esto incorporó al estudio la composición y el análisis de una suerte de sistemas viarios propios de las ciudades, que empezaron a ser denominados calle ciudad.

A la idea de corte de las "secciones urbanas" practicadas se superpuso el concepto de "mapa mental", el cual forma parte del lenguaje propio de la arquitectura surgido tras el posestructuralismo (Verga, 2006). El "mapa mental” tiene en la imagen ambiental de Lynch (1970) uno de sus orígenes, y puede definirse como un dibujo mental generalizado del mundo exterior retenido por un individuo: "producto al mismo tiempo de la sensación inmediata y del recuerdo de experiencias anteriores (...) para interpretar la información y orientar la acción” (pp. 12-13).

14 Nótese cómo otras corrientes de análisis morfológicos, como el Space Syntax, de tradición anglosajona y enfoque geográfico, no utilizan la elevación en sus representaciones, aunque sí como dato, conectándose a representaciones topológicas de tipo GIS con absoluto dominio de la planta (Ratti, 2004). Otras diferencias serían: un posicionamiento más determinista, una preponderancia del tiempo presente, de la cuantificación y a la búsqueda de patrones y tipos.

15 Ciudades entre 10.000 y 60.000 habitantes (Santa Fe, Antequera, Motril, Priego de Córdoba, entre otras). 
Un urbanismo que desarrollara su capacidad observadora precisaría siempre de este tipo de imágenes sintéticas que abarcan distintas escalas, relaciones y tiempos. En el contexto de la investigación que aquí se muestra, esta imagen que acaba por polarizar la ciudad fue denominada "universo urbano de la calle" y supuso, como hipótesis de partida, una composición de elementos urbanos relacionados (Rivas, 2012).

Así unidos, el "corte urbano" y el "universo urbano" aportan significado a la construcción de un elemento urbano complejo, la calle ciudad, por el que se apuesta para poder leer la ciudad a su paso, una "hipercalle" definida como un eje relevante de una entidad urbana, más el conjunto de elementos urbanos -casas, calles y espacios- articulados en torno a él, más allá incluso de sus bordes urbanos inmediatos, gravitando funcional y visualmente sobre él, elementos también de la geografía, de la historia y del paisaje de esa ciudad.

La calle ciudad es también un elemento relacionado con el tiempo. La relevancia o no de su traza depende de la evolución de la ciudad y del papel que este "sistema de relaciones" tiene en el momento de la observación. Así, por un lado, aunque es un elemento concreto, también es un elemento dinámico de fronteras difusas, y también, por otro lado, aunque es un elemento con un soporte físico relevante en la historia de la ciudad, su pertinencia como herramienta para la comprensión puede ser mayor o menor según épocas.

\section{Contribución a la forma urbis de la calle ciudad}

Desde un punto de vista social, la calle ciudad tiene la capacidad para registrar intereses tanto individuales como colectivos. Por un lado, este sistema es una construcción de los deseos de movimiento: una forma que concentra la mayor parte de los itinerarios personales o intenciones de desplazamiento, si consideramos este tipo de ciudad de tamaño medio que aún depende de esta "calle para todo" característica.

Por otro lado, la calle ciudad cumpliría con la función de mirar lo urbano, siendo uno de sus más singulares modos de hacerlo. Por ello, la elección del punto de vista sobre la calle representa el motor principal del corte, y contribuye a reflejar con mayor fiabilidad la esencia o identidad más profunda de la ciudad, integrándose en la forma urbis (Parcerisa, 2012). Y es que respecto al conjunto de formas urbanas relevantes de una ciudad, la calle ciudad supone casi una traslación escalar. El entramado de elementos y funciones es sustentado por una calle que es la de máxima urbanidad del momento, constituyendo un sistema de corte sobre el que puede crecer u orientarse la forma urbis, una especie de declinación (Figura 5).

Esta ligadura con la "forma esencial" de la ciudad permite a la calle ciudad establecer un equilibrio entre tiempos urbanos (formas heredadas, presente y futuro), constituyéndose como aquel conjunto de formas y relaciones a través del cual puede hacerse un mejor balance entre la historia urbana, la actualidad, y las aspiraciones o posibilidades urbanas de desarrollo. 
Figura 5 | Calle, ciudad y movimientos en Córdoba: (izq.) Vista aérea del Paseo de la Victoria en 1980; (der. superior) Esquema conceptual de sumatoria de líneas de deseo e intenciones de tránsito; (der. inferior) "Radiografía (I)" de la ciudad

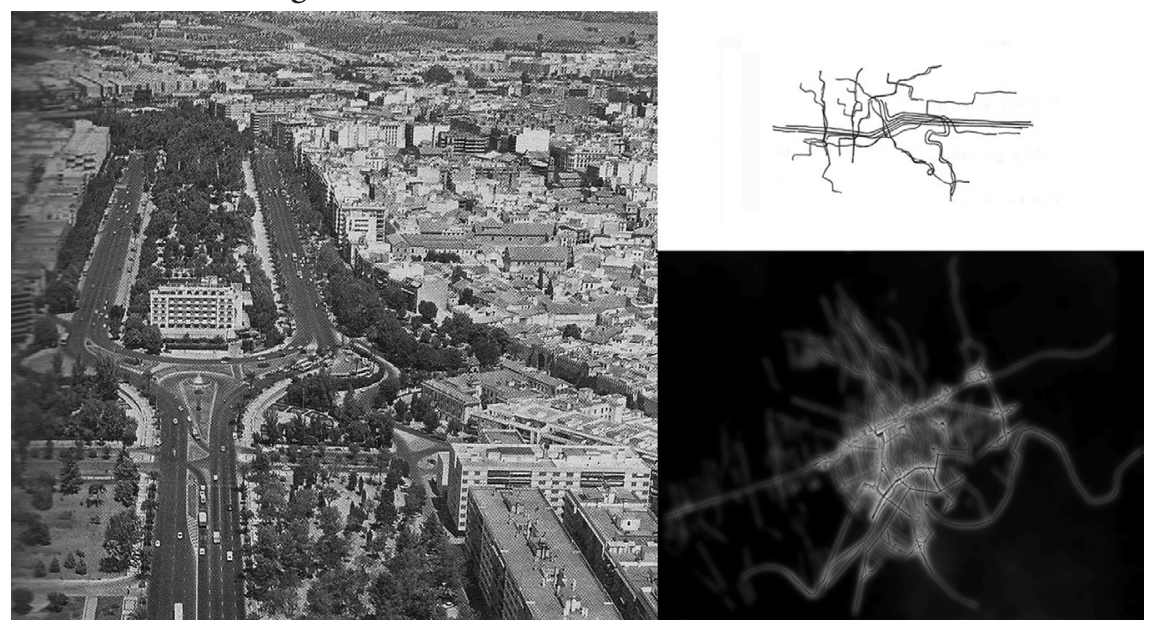

FUENTE (IZQ.) J. DIEZ, J. ARANDA Y F. RUBio, ANDALUCÍA (I980), P. 257; (DER. SUPERIOR E INFERIOR) ELABORACIÓN PROPIA

Atravesar y enlazar como mecanismos de conciliación fundamentales

Muchas de las planificaciones que se han elaborado en las últimas décadas en las ciudades estudiadas han mantenido una relación excesivamente lineal con los hechos urbanos: argumentos del tipo causa-efecto, diagnósticos estériles y soluciones "de manual", lecturas temporales como mera suma de etapas, zooms unidireccionales desde lo grande a lo pequeño, y visiones poco jerarquizadas del territorio.

La ciudad contemporánea ha demostrado con creces, en sus múltiples tipos y versiones, un comportamiento que en términos narrativos podría considerarse más teatral o fílmico: crecimientos apoyados en las infraestructuras, ciudades satélites asociadas a núcleos antiguos, vacíos y fronteras en los interiores urbanos, re- naturalizaciones, etcétera, según nuevos modos de apropiación de un territorio cambiante, conglomerados urbanos de tiempos y estilos difíciles de asimilar a través de una observación tradicional de los fenómenos.

La calle ciudad participa de este modus operandi más narrativo que permite descifrar la ciudad. Sus calles, arquitecturas y espacios poseen la capacidad para contarnos una historia, para convertirse en un canal por el que puede transitar la identidad del lugar. Esto es posible porque con la observación intensa a través del corte podemos llegar a profundizar en la mentalidad local, en un cierto pensamiento colectivo sobre el entorno. "El paseo suscita una gran cantidad de experiencias espontáneas que se entrelazan en el espacio urbano. En los complejos espacios de la ciudad moderna, los edificios no son tanto objetos como visiones parciales que forman un continuo en perspectiva. Filtrando nuestro movimiento, el horizonte es poroso, está en construcción o erosionado por el tiempo" (Holl, 1997, p. 12). Vista así, esta singular calle es un espacio "entrelazado" que mezcla visiones particulares y 
colectivas, y que, siendo susceptible de ser subdividido en ambientes locales, posee también la idea de continuidad o recorrido. Utilizada como metodología de estudio de lo urbano, es esta cualidad intermediaria entre lo local y lo global, capaz de identificar pautas de comportamiento y utilización del espacio, lo que permite abrir un abanico enorme de posibilidades.

\section{Metodologías para la calle ciudad}

\section{La mirada específica ciudad por ciudad}

La investigación propone una aproximación a cada territorio que se mueve mucho más en el campo de los procesos que en el de los productos, tanto en la fase de conocimiento como en la de formulación de las ideas. El objetivo es ofrecer herramientas para formar la opinión técnica del urbanismo en sus distintas disciplinas sobre lo que la ciudad es, cómo es y qué necesita, y poder construir así debates colectivos fundamentados que puedan enriquecer y afinar los programas. Frente a muchas políticas urbanas despegadas de la forma profunda del suelo y localizadas según lógicas de viabilidad -de tipo económico, político, etcétera-, demasiado inmediatas, se reclama una vuelta a lo físico en términos reales y no virtuales, una vuelta a un tipo de "proyecto" "tan preciso en sus líneas conceptuales como abierto y preparado para parciales o totales revocaciones, en continua oscilación entre los asuntos propuestos por las políticas de proximidad y articulación señaladas por los diferentes escenarios y situaciones a largo plazo" (Secchi, 2007, p. 282).

En relación con la calle ciudad, para conocer tales procesos urbanos debemos entender que se trata de un objeto de estudio específico y ajeno a límites administrativos. Todos los observables (las ciudades) depositan sobre esta "calle" el peso de asuntos muy importantes: las relaciones entre barrios, la accesibilidad al centro, la movilidad urbana, la conexión metropolitana, etcétera.

Esta dualidad objeto-observable justifica un método basado en dos acciones: la mezcla de instrumentos, mediante la intensificación e innovación de mecanismos de análisis; y la mezcla de ciudades, mediante una comparación implícita pero no lineal, una secuencia de operaciones o métodos situados en tres planos -uno por cada ciudad- relacionados pero independientes, descartando, en principio, categorías extrapolables de unas ciudades a otras.

\section{Las ciudades}

Las metodologías para cada ciudad podrían ser a priori intercambiables; sin embargo, cada observable específico exige una metodología ad hoc. Las razones para su elección están basadas en la experiencia y el conocimiento de los principales conflictos que cada ciudad anuncia y en la intuición que ayuda a entender más próxima una ciudad a un determinado enfoque (Figura 6).

Desde un punto de vista regional, las ciudades pertenecen a un mismo contexto: territorial, histórico, económico, cultural, social, etcétera. Comparten, además del mencionado rango escalar, una gran dificultad para la movilidad en los centros fundacionales, una excesiva consideración al automóvil en el conjunto urbano, una política municipal demasiado intervencionista en relación con las infraestructuras y los transportes, un viario debilitado, y aislados espacios de escala urbana. 
FIGURA 6 | Elección de un punto de vista en Córdoba: (izq.) Vista desde el NO de la ciudad, ferrocarril y Paseo de la Victoria; (der.) Esquemas metodológicos
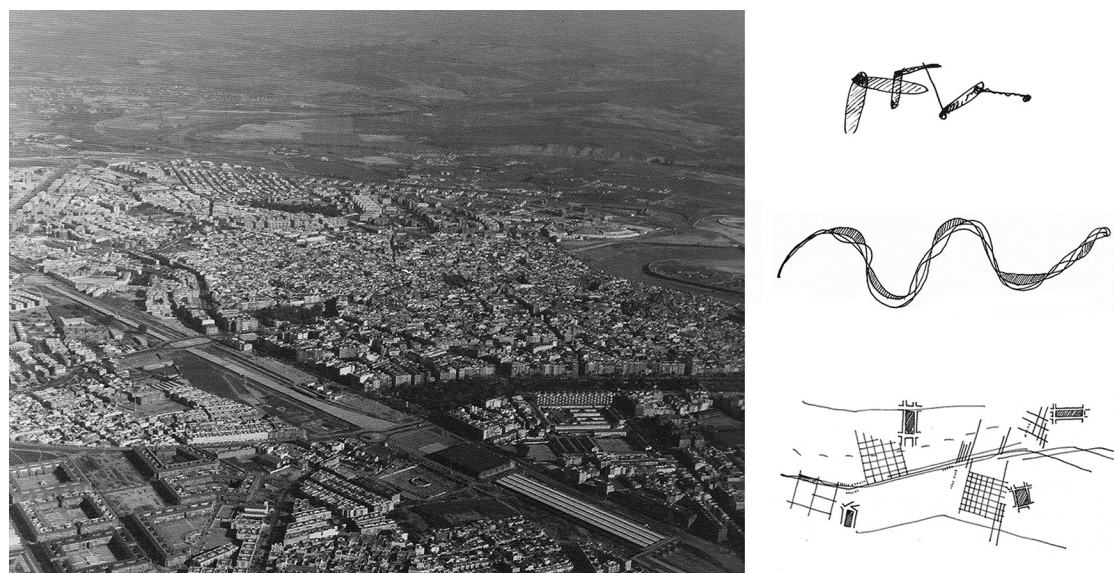

FUENTE (IZQ.) AVANCE DEL PLAN GENERAL DE ORDENACIÓN URBANA DE I 997 DE CÓRDOBA. GERENCIA DE URBANISMO DEL AYUNTAMIENTO DE CÓRDOBA; (DER.) ELABORACIÓN PROPIA

Córdoba es una ciudad que se ha movido poco desde su fundación, muy deudora aún de su forma histórica y de la lógica geográfica del río Guadalquivir. Sus cambios han sido muy paulatinos y suelen reincidir en las mismas posiciones. Esta fue la razón de apostar por una reconstrucción de su historiografía urbana, un proceso que "dibuja" la calle ciudad en el tiempo, acentuando ciertas cosas o personajes de la historia que exigirían hoy día una mirada más profunda.

Málaga es una ciudad construida por las infraestructuras: su fundación portuaria, el aeropuerto y su crecimiento en torno a él, su vinculación funcional con la ciudad región de la Costa del Sol, etcétera. Sin embargo, si atendemos a su forma urbis y más allá de algunos aciertos, Málaga no está sabiendo gestionar sus potentes recursos funcionales y formales. Por ello, la investigación observa la ciudad desde la perspectiva de un campo de fuerzas que provoca movimientos en torno a la travesía elegida. Los efectos que los distintos polos (históricos, turísticos, industriales o tecnológicos) provocan en los tejidos permiten deducir sus estados y sus capacidades para el cambio.

Granada es una ciudad formada desde el paisaje y movilizada por los poderes fácticos locales -al contrario de Málaga, que siempre tuvo intereses externos-. Su transformación o su inmovilismo han venido siempre de la mano de una "bondad" geográfica y una enorme dificultad económica. La dimensión paisajística es atendida desde la escala arquitectónica y la visión sensorial de las acciones en la calle (arquitecturas, esquinas, aceras...), lo que conecta el estudio con perspectivas cercanas, lejanas y de media distancia.

La elección de estas tres ciudades andaluzas, desde la distancia tan "iguales", permite demostrar más certeramente si cabe la especificidad de los hechos urbanos. Como tres líneas melódicas de una fuga de Bach, las ciudades producen recorridos ligeramente similares que al entrelazarse muestran, sin embargo, las diferencias en altura, ritmo y dinámica, todas contribuyendo a la composición global. 
Tal y como refleja el cuadro de metodologías de la investigación (Cuadro 1), la suma de las distintas metodologías ofrece una variedad analítica que, más allá de su propio enfoque y sus objetivos, da cuenta de la importancia del papel multidimensional que el urbanismo contemporáneo puede llegar a ofrecer. En este cuadro pueden observarse las distintas categorías, observables y escalas, así como la instrumentación y los criterios de cada acción.

\section{CUADro I | Cuadro de metodologías de la investigación}

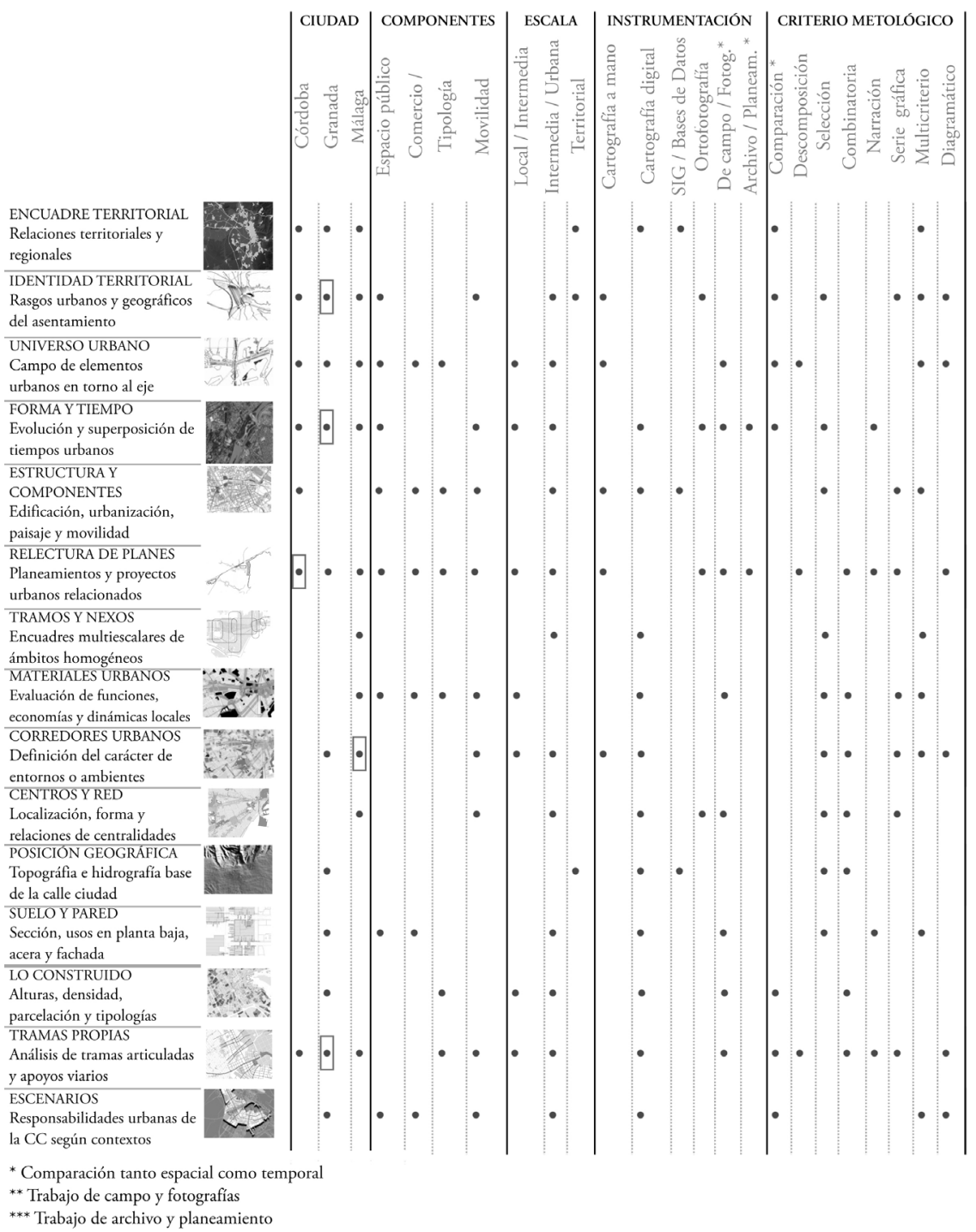

FUENTE ELABORACIÓN PROPIA 


\section{Instrumentos y elementos estudiados}

De entre las distintas acciones utilizadas en la observación podrían destacarse tres, fundamentales a la hora de producir los resultados:

a. "La comparación temporal": interpretación de "retratos" claves en la historia de la ciudad.

b. "La descomposición de los elementos del plano": comprensión de la calidad y cantidad de los materiales urbanos, aislados o formando conjuntos.

c. "La yuxtaposición orientada": mezcla e interacción de componentes, la combinatoria de lo diferente.

Estas acciones son necesarias para generar cartografías que, en cierta medida, deconstruyen la realidad, componiendo series más o menos amplias que precisan ser leídas como dinámicas o vivas, dúctiles a los cambios y oportunidades de las ciudades.

Los distintos asuntos abordados se agrupan en torno a cinco bloques temáticos que reúnen dimensiones espaciales y morfológicas de las ciudades en torno a cada calle ciudad (Cuadro 2), así como aquellas otras dimensiones que expresan relaciones externas y registran procesos significativos que motivan la situación actual ${ }^{16}$.

\section{CUADro 2 | Bloques temáticos de la investigación sobre la "calle ciudad”}

\begin{tabular}{|l|l|}
\hline FORMA & $\begin{array}{l}\text { Identificación de elementos implicados en la calle ciudad ahora } \\
\text { y en el futuro, asi como aquellos que formaron parte de su } \\
\text { construcción }\end{array}$ \\
\hline ESTRUCTURA & $\begin{array}{l}\text { Cualificación de sus tramos, propuesta de tramos o el estable- } \\
\text { cimiento de diferencias, relaciones con escalas territoriales o } \\
\text { metropolitanas }\end{array}$ \\
\hline PAISAJE & $\begin{array}{l}\text { Nuevos espacios públicos, nuevos lugares para arquitectura emer- } \\
\text { gente, nuevas perspectivas y nuevos paisajes }\end{array}$ \\
\hline FLUJOS & $\begin{array}{l}\text { Políticas internas o relacionadas con los movimientos: circulación, } \\
\text { aparcamientos, cualidad de las aceras, sección viaria, transversa- } \\
\text { lidad, accesibilidad, funciones atractoras, etc. }\end{array}$ \\
\hline ESCENARIOS & $\begin{array}{l}\text { Nuevas representaciones futuras que sumen al imaginario } \\
\text { de las entidades observadas, compromisos y papeles urbanos } \\
\text { transescalares }\end{array}$ \\
\hline
\end{tabular}

FUENTE ELABORACIÓN PROPIA

16 Estas dimensiones estudiadas reúnen bases para la evaluación crítica de aspectos y lugares en las ciudades que son reflejo de muchas otras dimensiones (económicas, demográficas, ambientales, culturales o sociales), interpretadas aquí a través de sus repercusiones espaciales, visuales y funcionales. Las ciudades necesitan de enfoques específicos capaces de profundizar también en estas otras dimensiones, al tiempo que interactúan con los supuestos de esta investigación. 


\section{Cartografías interesantes de las ciudades observadas}

Como muestra de la actitud recopilatoria, multiescalar y multitemática de la investigación, se han elegido tres ejemplos de metodologías sobre Córdoba, Málaga y Granada. La observación se ha caracterizado por la prudencia en la extracción de las conclusiones, habiéndose dado prioridad a la crítica de la realidad frente a la definición exacta de las medidas por adoptar, y apostando por abrir el debate local acerca de ciertos asuntos centrales.

\section{Estructura y formación de la calle ciudad de Córdoba}

En un intento por comprender el sistema de la travesía, se consideró importante reconocer sus diferentes partes y establecer un cierto orden general del que pueda emanar una "estructura modelo". La lógica territorial y la característica sedimentación histórica de Córdoba eran rasgos de la ciudad muy favorables para este enfoque.

En un primer trabajo se estudiaron determinados espacios en tiempos correlativos, superponiendo momentos distintos de su historia urbana. Mediante la interpretación de ortofotografías (1936, 1956, 1977 y 2007) se trató de entender la evolución de la ciudad desde las primeras trazas de la calle ciudad, centrada en el Paseo de la Victoria, así como reconstruir el proceso de formación de este sistema y su relación con momentos significativos de la ciudad (Figura 7).

\section{FIGURA 7 | La calle ciudad de Córdoba en 1936, 1977 y 2007}
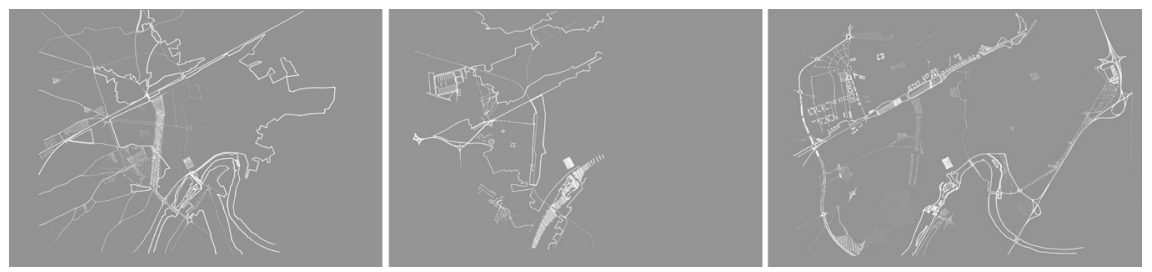

FUENTE ELABORACIÓN PROPIA

El segundo trabajo se basó en la separación de los elementos que componen actualmente la estructura. Contando con la máxima información posible, se logró extraer una completa taxonomía que permitió elaborar una teoría acerca de los elementos urbanos constituyentes de la calle ciudad. De esta manera se detectaron y definieron distintos conceptos importantes: directriz principal, transversal estructurante, borde de calle, ámbito inmediato, apoyos secundarios, ejes de continuidad y complementarios, huella geográfica del sistema, etcétera.

Este trabajo permitió nombrar concretamente los "objetos" de la calle ciudad, y estudiar su aplicación en las otras ciudades de la investigación. El desplazamiento de tal modelo teórico según las especificidades de cada ciudad fue algo fundamental, reformulándose según el caso alguno de estos conceptos (Figura 8). 
FIGURA 8 | La estructura de la calle ciudad de Córdoba: (de izq. a der. y de arriba abajo) "El espacio interior a la cota +150 ", "La transfiguración de la calle en río", "Piezas del territorio urbano" y "La ciudad y el suelo de la calle ciudad"

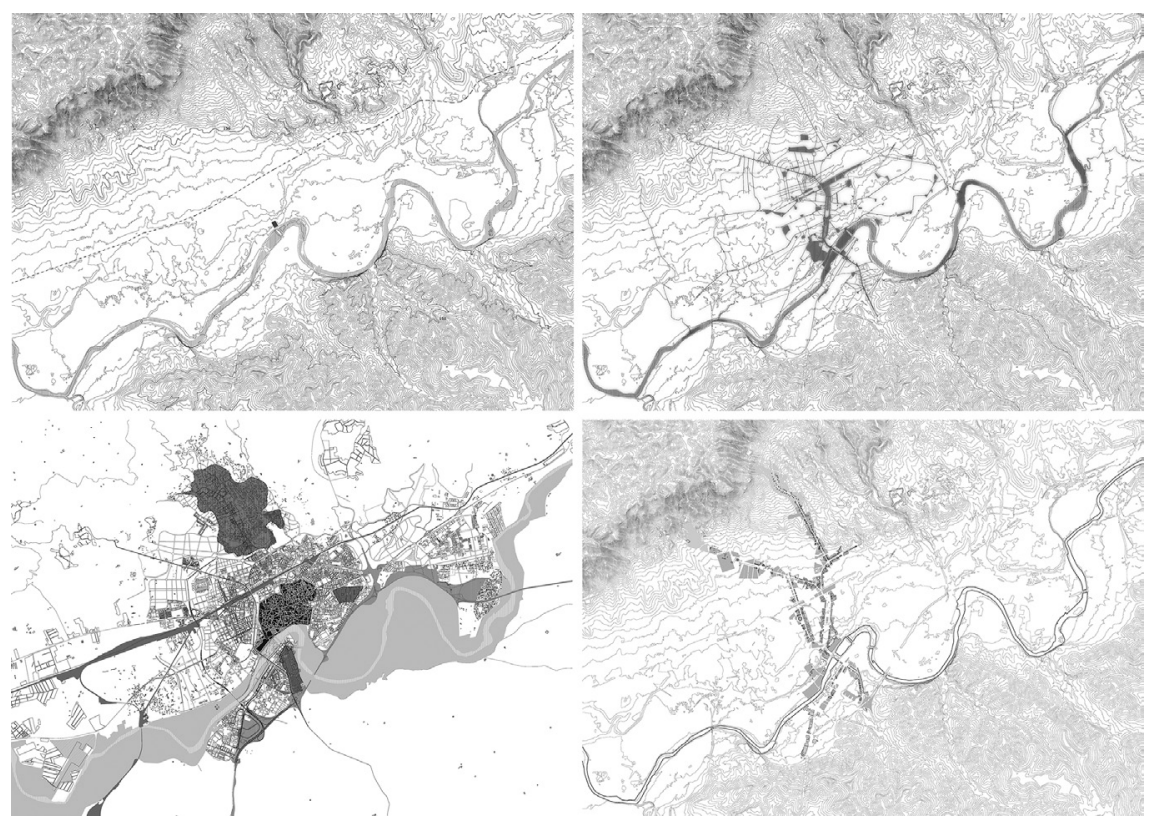

FUENTE ELABORACIÓN PROPIA

\section{Infraestructuras y corredores urbanos en torno a la travesía de Málaga}

La red de espacios públicos, el conjunto de equipamientos y servicios urbanos, o las grandes superficies comerciales atractoras de tráfico, son elementos tradicionalmente considerados para evaluar las dinámicas urbanas ${ }^{17}$. Sin embargo, en la mayoría de los casos, los análisis de movilidad o de flujos habituales no logran trascender de una escala urbana global, lo que simplifica la entrada de información y homogeneiza sus posibles conclusiones. En el caso de Málaga se propuso una visión local de las fuerzas urbanas, un análisis de los polos o centros urbanos y efectos espaciales de estos en torno a la travesía (tipos de movimientos, éxito de sus espacios públicos, déficit de dotaciones, etcétera).

Elegido un encuadre local de estudio que se consideró trascendente ${ }^{18}$, se fijaron dos objetivos:

a. Sistematizar los materiales urbanos: diversificarlos, categorizarlos y cartografiarlos según tipos.

b. Estudiar la variable peatonal: establecer un sistema relacional complejo y rico con los elementos detectados, usando conceptos como entorno, corredor y red.

17 A través, por ejemplo, de la construcción más o menos literal de matrices o/D (Origen-Destino).

18 Un tramo prolongación de la Alameda al oeste del río Guadalmedina: la Avenida de Andalucía hasta la Ronda Oeste de Málaga. 
Para ello se generaron varias "series gráficas" que agrupaban los asuntos urbanos enunciados (Figura 9):

- estructura urbana de lo colectivo (espacio público, equipamientos y redes urbanas y metropolitanas de transporte);

- estructura local de lo colectivo (información precisa del encuadre o tramo central del eje);

- corredores urbanos (conjuntos urbanos según tipo y localización de espacios libres, y análisis de los tejidos);

- corredores dotacionales (ámbitos de influencia de equipamientos en relación con la accesibilidad y la estructura urbana).

Así, a través del aumento en la precisión y profundidad de la observación de los materiales de la estructura colectiva y sus movimientos, quedaron definidas dos herramientas nuevas de análisis y proyecto muy interesantes, relacionadas con la forma y el proyecto de la calle ciudad: la "intermodalidad local" y la "difusión peatonal", que fortalecen, cohesionan y dan urbanidad al entorno seleccionado de la travesía ${ }^{19}$.

FIgura 9 | Encuadre local de la calle ciudad de Málaga: (izq.) Corredores urbanos; (der.) Ámbitos de intervención producto de la superposición de los distintos corredores espaciales

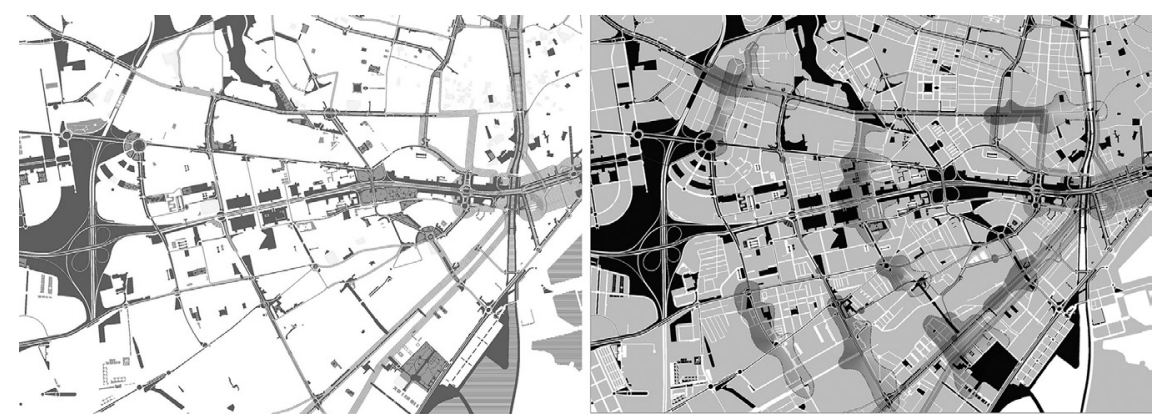

FUENTE ELABORACIÓN PROPIA

\section{Tramas y escenarios de responsabilidad de la calle ciudad de Granada}

En relación con el ámbito del Camino de Ronda, Granada ha tenido que reconocer la capacidad aglutinadora de esta travesía, así como la utilidad y legibilidad de su posicionamiento urbano y territorial. Todo ello a pesar de circunstancias que dificultaban esta lectura positiva: la construcción de la carretera de Circunvalación, que representó la negación del futuro de su ámbito urbano; la ausencia de buenos proyectos urbanos de fortalecimiento; y la crítica constante a su pésima consolidación arquitectónica (Rivas, 2011).

19 En este ámbito se han desplegado recientemente las dos primeras líneas de metro, resultando relevante el estudio de la influencia de las estaciones en el tejido urbano y su articulación en la red peatonal. 
El sistema de la calle ciudad en torno al Camino de Ronda en Granada muestra cómo la propia ciudad es: muy abierto en sus extremos, con muchas posibilidades o alternativas, y muy cerrado en su centro, cargado de prejuicios que impidieron mejores horizontes (Parcerisa, 2012). Para superarlos, la ciudad necesita entender su pasado mediante una actitud proyectual que formule las preguntas adecuadas, aumentando las conexiones de la traza tanto con la ciudad como con su territorio. La combinación entre experiencia y crítica, entre intuición e información, ha servido para observar Granada desde cuatro secciones temáticas: la traza, el interior, la arquitectura y los escenarios.

Las tres primeras construyen una paleta de argumentos físicos, emocionales y funcionales con que vislumbrar la cuarta: la "traza" nos remite al gesto de fundación de la calle y su relación posicional con Granada; el "interior" lee las cualidades físicas de la calle como contenedor de pequeñas formas urbanas, de apariencias y acciones motivadas por sus contornos; la "arquitectura" descifra las decisiones puramente técnicas (las actuaciones urbanísticas, las tramas propias o asociadas, su grano pequeńo) que convierten a la calle ciudad en lo que hoy es.

Cada "escenario" es entendido como una visión surgida de aislar determinadas funciones del sistema y observar sus repercusiones. Tales escenarios son suplementarios y, tal y como lo describe Secchi (2007), pueden resultar incluso parcialmente contradictorios, lo que precisamente los hace más interesantes. Estos terminan por situar la calle ciudad en un plano abstracto que permite conferirle diferentes "responsabilidades": escenario "urbano", "periférico" y "central". Son cambios de perspectiva de la calle que la reivindican, respectivamente, como soporte de la identidad del barrio que articula; relacionada con el interior central de la ciudad; o partícipe de una dimensión territorial cada vez más activa (Figura 10).

Figura io | Tramas y escenarios de la calle ciudad de Granada: (izq. superior) Superposición de las tramas; (izq. inferior) Ortofotografía del contacto central ciudad-campo; (der.) "Escenario urbano"

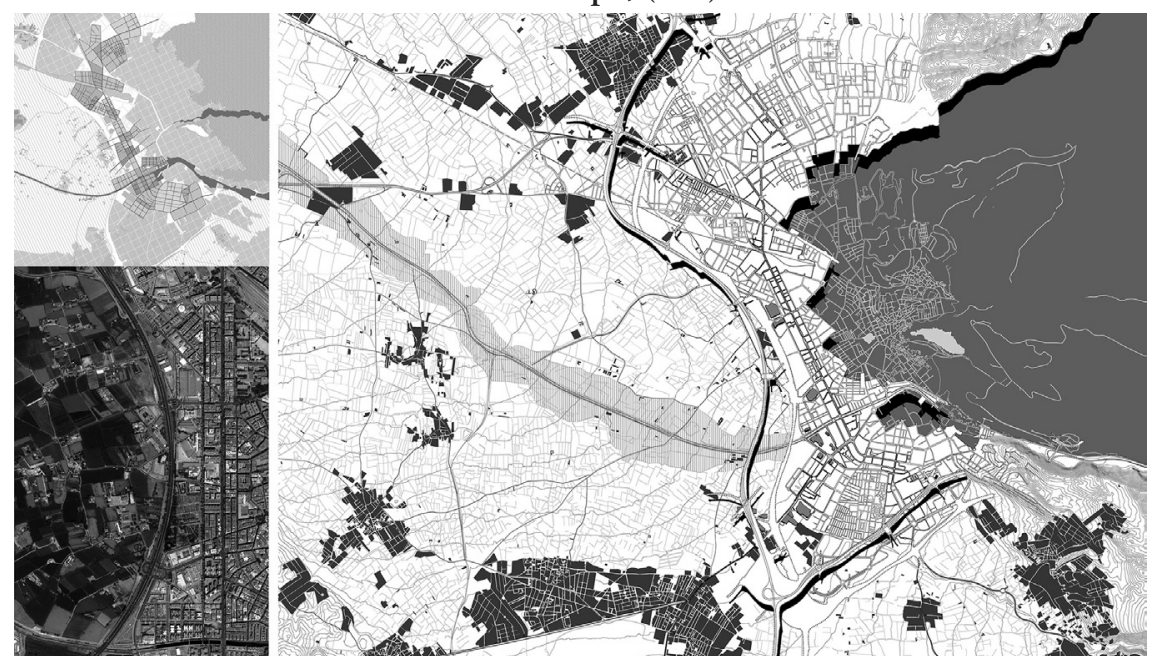

FUENTE ELABORACIÓN PROPIA 


\section{Hacia un urbanismo contemporáneo de la observación}

Márgenes de maniobra en Córdoba, Málaga y Granada

Los ensayos descritos muestran la calle ciudad como un instrumento al servicio de la interpretación y evaluación tanto de su entorno cercano como del conjunto urbano que "atraviesa". Los resultados de esta herramienta pretenden ser útiles por sí mismos, y ello al margen de que ella pueda encadenarse con lógicas metodológicas mayores, principal línea abierta de la investigación. Se trataría de profundizar en su integración en procesos analíticos de búsqueda en donde otras dimensiones de la cuestión urbana -economía, sociología, medioambiente, etcétera- también alcancen un grado de madurez suficiente.

Así, por ejemplo, las distintas cartografías elaboradas se muestran como asociaciones teóricas extrapolables a otros procesos de observación de lo urbano, presentando, entre otras, visiones sintéticas de la relación de las calles y ciudades con las poblaciones y entornos urbanos metropolitanos. Sin embargo, al mismo tiempo, estos trabajos ofrecen información propia y relatan cualidades y déficits locales particulares. Todo ello es reflejo de una doble bidireccionalidad muy positiva: de un lado, entre teoría y práctica; del otro, entre lugar y objeto, esto es, el lugar hace el objeto y el objeto construye y nombra lugares, los cualifica.

Resulta difícil exponer las conclusiones de todo el trabajo desarrollado, tanto aquellas relacionadas con el objeto de estudio (conclusiones generales), como las específicas sobre las ciudades estudiadas. Las conclusiones más relevantes se reflejan en el Cuadro 3, donde se señalan sus rangos o temáticas. Ellas suponen, además, algunas de las líneas abiertas para el trabajo posterior que el urbanismo de estos territorios podría acometer. La multiescalaridad, la especificidad del objeto de estudio, la versatilidad de la correspondencia entre métodos y ciudades, la necesidad de relación interna entre acciones de la observación, la necesidad de sistemas abiertos que puedan incorporar otras metodologías en el futuro (encuestas, bases de datos, talleres colectivos, panel de expertos, sectorialidades...) son algunas de las lecturas que este cuadro ofrece.

A la vista de estas conclusiones y en relación con la calle ciudad y con su fortalecimiento como sistema útil para orientar la comprensión y el proyecto de las ciudades estudiadas, pueden destacarse los siguientes aspectos: la insistencia en la conexión con la geografía evolutiva del asentamiento; la necesidad de cohesionar y enriquecer el sistema, darle continuidad y mayor capacidad de atravesamiento; la necesidad de observar su potencial como centralidad en red con otras pulsiones urbanas relevantes; y su papel de protección y articulación de barrios, elementos naturales y patrimonios urbanos relacionados.

\section{Criterios para la observación}

Animar a la producción de otros puntos de vista interesantes es uno de los objetivos ulteriores de este dispositivo teórico y metodológico, útil para el reconocimiento del territorio mediante la suma, el contraste y la profundidad de cada enfoque. Tal y como Geddes (1915/2009) proponía, la calle ciudad confecciona, a través de un instrumento teórico-práctico, un nuevo lenguaje de la observación que se añade a lo preexistente, tanto desde el punto de vista espacial como temporal (Cuadro 4). 


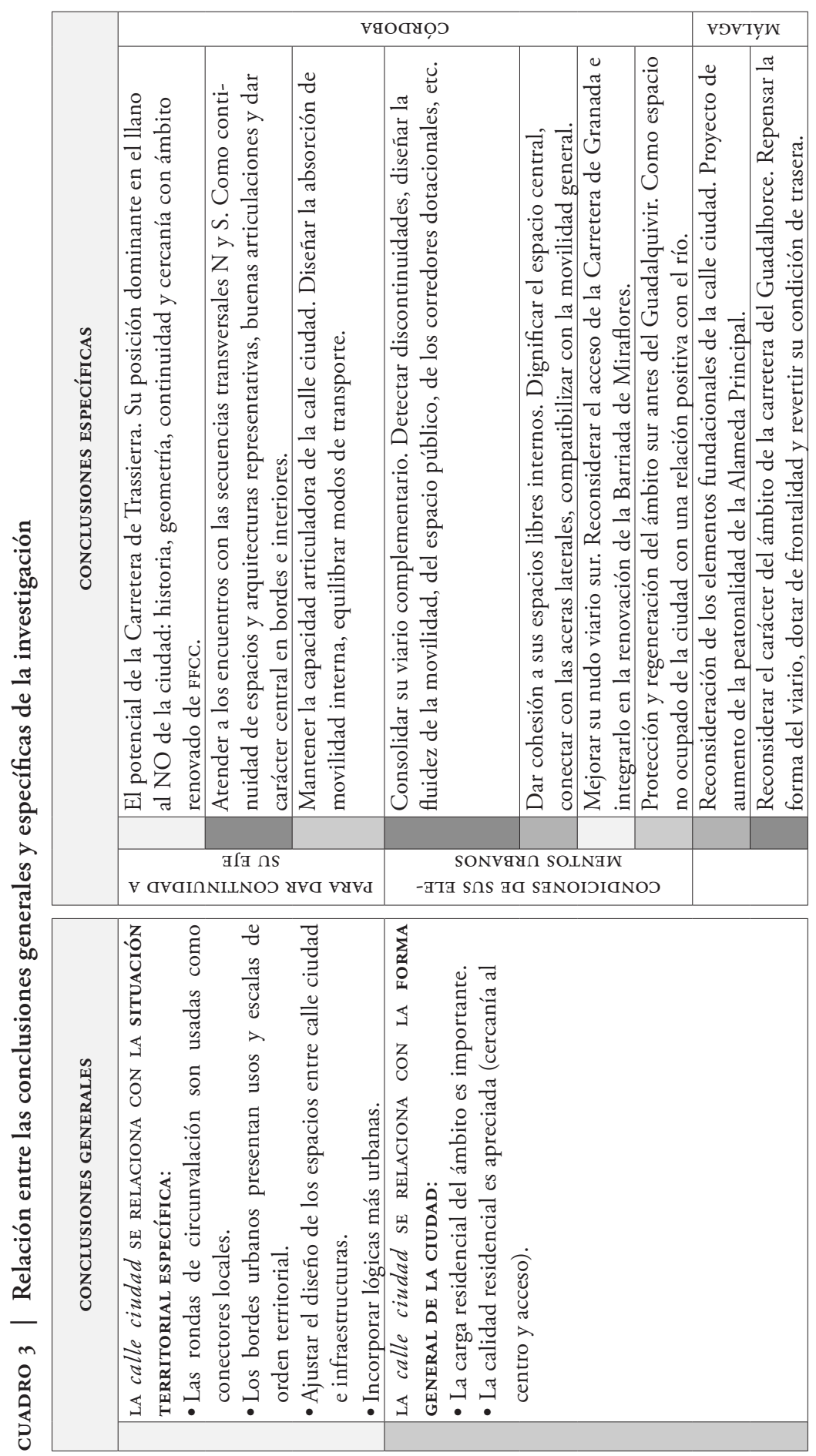



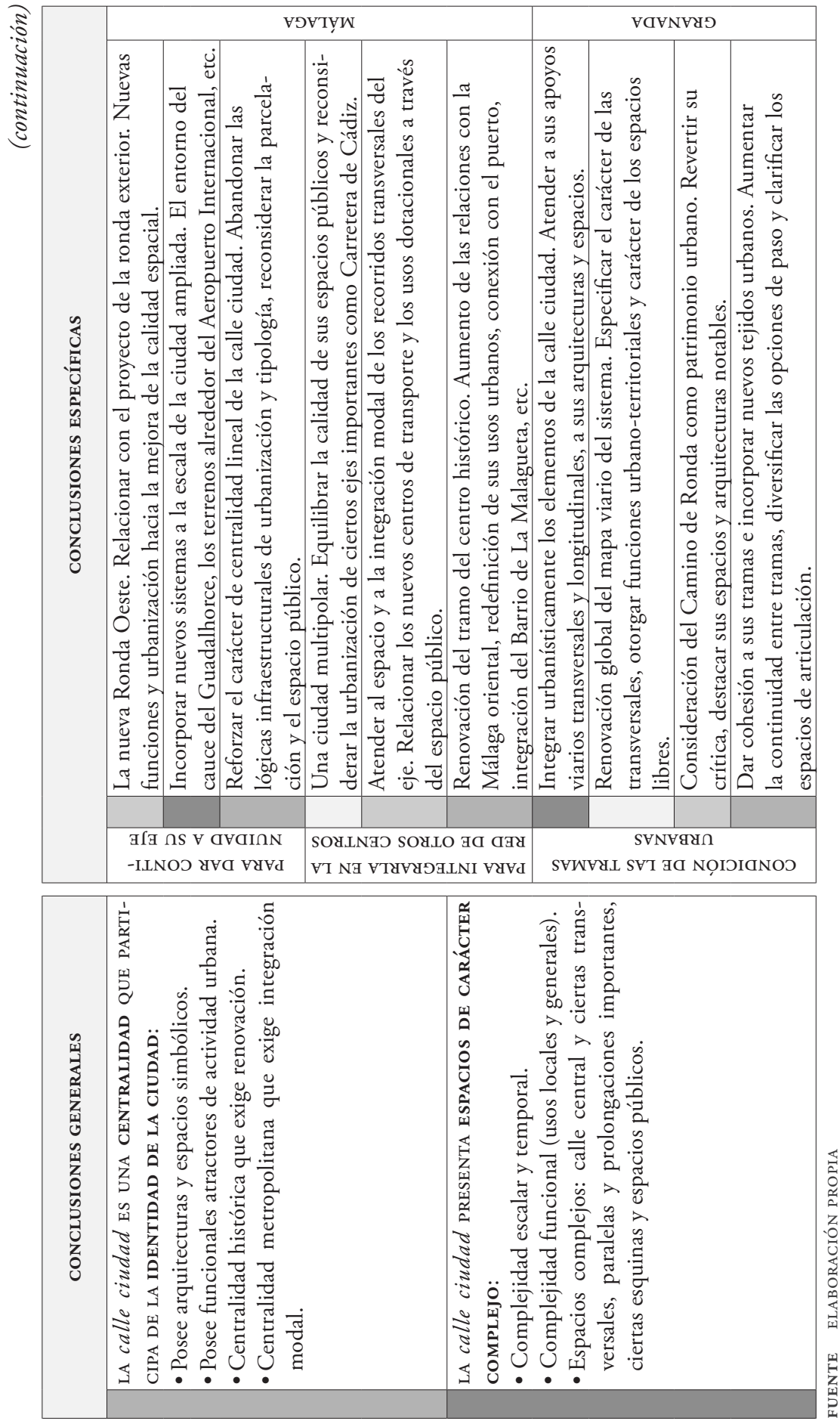
CUADRO 4 Criterios contemporáneos para la observación

\begin{tabular}{|l|l|}
\hline LECTURA & $\begin{array}{l}\text { Búsqueda de elementos que comprometan interpretaciones superpuestas } \\
\text { MULTIESCALAR } \\
\text { ciudad región, territorio urbano, etc. }\end{array}$ \\
\hline \multirow{2}{*}{ ANÁLISIS SINTÉTICO } & $\begin{array}{l}\text { Procesos de estudios urbanos que parten de problemáticas o dinámicas es- } \\
\text { tructurales, pero que comprueban sus efectos en las dimensiones cercanas: } \\
\text { paisaje local, funciones de la calle, cualidad de los lugares involucrados, } \\
\text { etc. }\end{array}$ \\
\hline BÚSQUEDA DE ASUNTOS \\
CLAVE & $\begin{array}{l}\text { Renuncia a la planificación general habitual en pro del hallazgo de } \\
\text { lecciones valiosas sobre la ciudad y para la ciudad, con la voluntad de ser } \\
\text { útil como herramienta de análisis y orientación para otras planificaciones } \\
\text { futuras. }\end{array}$ \\
\hline ATENCIÓN & $\begin{array}{l}\text { Compromiso equitativo con los distintos tiempos urbanos, a través de la } \\
\text { lectura y la interpretación de pasado, presente y futuro: formas fundacio- } \\
\text { Males, acontecimientos clave en su desarrollo y evaluación de transforma- } \\
\text { ciones posibles. }\end{array}$ \\
\hline ANÁLISIS PROYECTIVO & $\begin{array}{l}\text { Imbricación entre las acciones de análisis y de proyecto, utilizando razona- } \\
\text { mientos propositivos autónomos que reactivan la observación y mueven a } \\
\text { nuevos cuestionarios analíticos. }\end{array}$ \\
\hline
\end{tabular}

FUENTE ELABORACIÓN PROPIA

El urbanismo que toca, aun surgiendo del contexto de las ciudades estudiadas, es reconocible universalmente, en mayor o menor medida, y está enraizado en la tradición urbanística clásica desde distintas disciplinas. Tal urbanismo debería alejarse de aquellos hábitos de la planificación basados en estrategias de acción como aplicación exclusiva y directa de "soluciones-tipo" o "soluciones-manual" y, al contrario de lo que parece estar sucediendo mayoritariamente, al menos en el sur de España, ir más allá de la diagnosis que responde a cuestionamientos "disciplinares" prefijados.

Estas ciudades necesitan que el urbanismo acerque su teoría a su práctica, deje de aplicar recetas y apueste por líneas de trabajo específicas a medio y largo plazo, en lugar de la terrible preponderancia del tiempo corto, que lo hace depender excesivamente del momento político o económico. Urge un urbanismo que priorice el conocimiento de la ciudad a su transformación, y limite las actuaciones y proyectos a aquellos que son fruto de una demanda muy racionalizada, comprendida y consensuada.

Es necesario construir, entre todos, un urbanismo más cartográfico y participativo, preocupado por hacerse entender y dar la palabra a todos; un urbanismo que logre antes que nada entenderse a sí mismo, representando adecuadamente sus propias interpretaciones. Es clave saber crear imágenes valiosas que trasciendan de las decisiones que puedan acompañarlas, encontrar criterios e ideas que se conviertan en patrimonio cultural de una sociedad que se pregunta constantemente sobre sí misma y trata de armarse para los cambios y los progresos. 


\section{Referencias bibliográficas}

Alexander, C. (1977). A pattern language: towns, buildings, construction. Nueva York: Oxford University Press.

Corboz, A. (2004). El territorio como palimpsesto. Lo urbano en 20 autores contemporáneos (pp. 25-34). Barcelona: Edicions de la Universitat Politècnica de Catalunya.

Dematteis, G. (2006). En la encrucijada de la territorialidad urbana [Sul crocevia della territorialità urbana]. Bitácora Urbano-Territorial, 1(10), 53-63. En http://www. redalyc.org/articulo.oa?id=74801006

Eisenman, P. (1995). El "zeitgest" y el problema de la inmanencia. AV Monografías, (53), 27-32.

Gandelsonas, M. (1999a). The city as the object of Architecture. X-Urbanism: Architecture and the American city (pp. 59-71). Nueva York: Princeton Architectural Press.

Gandelsonas, M. (1999b). Drawing the American city. X-Urbanism: Architecture and the American city (pp. 75-78). Nueva York: Princeton Architectural Press.

Geddes, P. (1915/2009). Ciudades en evolución. Oviedo: KRK Ediciones.

Gómez, J. L., Grindlay, A. \& Valenzuela, L. M. (2004). Movilidad y vivienda en los centros históricos. Análisis en ciudades medias andaluzas. Sevilla: Consejería de Vivienda y Ordenación del Territorio, Junta de Andalucía.

Holl, S. (1997). Entrelazamientos. Barcelona: Gustavo Gili.

Lynch, K. (1970). The image of the city. Cambridge, MA: The MIт Press.

Mcharg, I. (2000). Proyectar con la naturaleza. Barcelona: Gustavo Gili.

Meyer, H. (2005). Del plan al proyecto y hacia la perspectiva. Los territorios del urbanista. 10 años (pp. 41-49). Barcelona: Edicions de la Universitat Politècnica de Catalunya (UPC).

Parcerisa, J. (2012). Forma urbis. Cinco ciudades bajo sospecha. Barcelona: Laboratori d"Urbanisme de Barcelona, Universitat Politècnica de Catalunya (UPC).

Portas, N., Domingues, A. \& Cabral, J. (2007). Politicas urbanas. Tendências, estratégias e oportunidades ( $2^{\mathrm{a}}$ ed.). Lisboa: Fundação Calouste Gulbenkian.

Ratti, C. (2004). Urban texture and space syntax: some inconsistencies. Environment and Planning B: Planning and Design 31, 487-499.

Rivas, J. L. (2006a). La multiescala obligatoria. Un curso de urbanismo 2002-2003. Proyectos urbanos y territoriales en el Área Metropolitana Sur de Granada (pp. 36-45). Granada: Universidad de Granada.

Rivas, J. L. (2006b). Redes temporales. Un curso de urbanismo 2003-2004. Proyectos urbanos y territoriales en el Litoral de Granada (pp. 46-57). Granada: Universidad de Granada.

Rivas, J. L. (2011). Visiones de una traza moderna. El Camino de Ronda, Granada. PAPERS D"UR, (2), 114-121. En http://hdl.handle.net/2099/11570

Rivas, J. L. (2012). La travesía más transparente. La visión de Córdoba, Málaga y Granada desde su calle ciudad (Tesis doctoral). Granada: Universidad de Granada.

Secchi, B. (1984). Le condizioni sono cambiate. Casabella. Architettura come modificazione, (298-99, enero-febrero), 8-13. En http://www.cittasostenibili.it/html/Scheda_17.htm

Secchi , B. (2007). Urban scenarios and policies. Políticas urbana. Tendencias, estrategias y oportunidades (2a ed., pp. 274-283). Lisboa: Fundação Calouste Gulbenkian.

Soja, E. (1998). Seis discursos sobre la postmetrópolis. Urban, (2), 43-57. En dialnet.unirioja. es/descarga/articulo/3656692.pdf [versión bilingüe, inglés-castellano]. 
Solà-Morales, I. (1989). Cuatro notas sobre la arquitectura reciente de Peter Eisenman. El Croquis, (41), 16-23. En https://bibliodarq.files.wordpress.com/2012/07/08-solc3a1morales-i-cuatro-notas-sbre-la-arquitectura-de-p-e.pdf

Solá-Morales, M. (1981). La identidad del territorio. Quaderns d"arquitectura i urbanisme, (Extra $\mathrm{n}^{\circ}$ 1), 3. En http://lub.upc.edu/web/Arxiu/Recerques/comarques/articles_ castella/identidad_territorio_cast.pdf

Solá-Morales, M. (1987). Segunda historia del proyecto urbano. UR (El Proyecto Urbano I), (5), 21-27. En http://hdl.handle.net/2099/3118

Solá-Morales, M. (2008). Ciudades cortadas. De cosas urbanas (pp. 174-183). Barcelona: Gustavo Gili.

Verga, M. (2006). Lessico: Mappe mentali. Lotus International (Diagrams), (127), 23.

Viganò, P. (2001). Territories of a New Modernity. Nápoles: Editor Electa.

Zahonero, A. (2009). Nuevos usos para antiguos territorios. Paisea. Revista de Paisajismo, (11), 105-111. 